\title{
QUALITY CONTROL TOOLS IN THE ANALYSIS OF COVID-19 CAUSED PROBLEMS
}

\author{
Nicolas Dominguez-Vergara ${ }^{1}$, \& Daniel Nicolas Dominguez-Perez ${ }^{2}$ \\ ${ }^{1}$ Universidad Autónoma Metropolitana (Mexico) \\ ${ }^{2}$ Universidad Nacional Autónoma de México (Mexico)
}

\begin{abstract}
Quality control tools are taught in engineering careers to analyze and try to solve problems in the production of goods and in the performance of service businesses. Those tools can be used to analyze and understand many problems. The coronavirus pandemic has caused many problems around the world, like many people infected in people's agglomerations in public transportation, in celebrations like parties, in political rallies and in public markets because of the people not wearing masks. A Pareto diagram clearly shows the most dangerous comorbidities in case of covid-19 infection. A lot of doctors and nurses have been contagious around the world in many cases because of lack of protection materials for them, hopefully health and safety procedures (check lists) and Poka Yoke devices are being created and implemented to reduced contagion. In this paper we identified and analyzed some covid-19 caused problems using basic quality control tools and for some cases we proposed solutions to them. Examples of a Pareto Diagram in analyzing the death rate in age ranges is used to explain the decrement in deaths in the United States of America if certain age groups are first vaccinated, an Ishikawa Diagram is used to analyze the ineffective distant learning in Mexico, a Check List is elaborated to avoid contagion in shopping and a Dispersion Diagram is used to find a relation between the number of contagious and the number of deaths in many countries of the world. Some other tools are briefly explained and some problems which could be analyzed with those are identified. The examples could enhance the interest of the students in learning the usefulness of those tools in a variety of fields.
\end{abstract}

Keywords: Teaching-learning process, covid-19.

\section{Introduction}

There are plenty of examples of the usefulness of quality control tools to analyze industry problems or even to find solutions for them. For example, in the April 26, 1986 nuclear accident in Chernobyl a simple analysis shows that a Check List mirroring its nuclear safety procedure could have been very useful to avoid the accident together with a Poka Yoke device (a double container system). The nuclear accident in Fukushima on March 11, 2011 could possibly have been prevented using taller walls against high tides and water tanks on towers nearby the nuclear reactors (both Poka Yoke devices). Also, a simple Check List on the right metric system of measurement to use during the whole trip to Mars could have avoided the disaster of the Mars Climate probe on September 23, 1999. The covid-19 pandemic has caused alarm in many countries because of the number of contagious and deaths of their people. The countries have followed very different strategies trying to reduce contagion, hospitalizations and the number of deaths. In this paper quality control tools (Gutierrez \& de la Vara, 2013) are used to understand some of the problems that the pandemic has caused (Dominguez-Perez \& Dominguez-Vergara, 2020) (Dominguez-Vergara \& Dominguez-Perez, 2020) and to analyze some of the data available. The aim is that the students learn that these tools can be used to analyze problems beyond engineering. Examples in which a Pareto Diagram, an Ishikawa Diagram, a Check List and a Dispersion Diagram are used, are reported in this paper.

\section{Pareto diagram}

The Pareto Diagram is very useful to identify which are the most important problems that are needed to be addressed in a situation (Gutierrez \& de la Vara, 2013). This diagram is also called the $80-20$ Diagram because in the classic example $80 \%$ of the accumulated frequency of the problems is caused only by $20 \%$ of them. That is, there are many trivial problems but only a few vital, the $20 \%$ of the problems, and it is recommended that these are resolved. In a lot of cases, the classic Pareto Diagram it is not the outcome, 
that is, not exactly the $20 \%$ of the problems are vital. In those cases, decision makers must decide which problems to solve depending on the available human and material resources. Also, sometimes it is necessary to consider other issues as in the example given bellow. The students learn that some research has to be carried out in order to better understand the problem being analyzed.

In the first example, a Pareto Diagram is used regarding the decision of which part of the population must be vaccinated first in the United States. The determination has been reached in many countries that medical personnel must be first in line, then older people because they have died more. The first column of Table 1 contains the age group, the second column the covid-19 mortality rates in deaths by 100000 inhabitants in the United States of America (US) (US Center for Disease Control and Prevention, 2020) and the third column is the percentage of accumulated mortality rate.

Table 1. Covid-19 mortality rates by age range in the US and their accumulated frequency.

\begin{tabular}{|l|l|l|}
\hline Age range & Mortality rate & $\begin{array}{l}\text { Percentage of accumulated } \\
\text { mortality rate }\end{array}$ \\
\hline $85+$ & 1118.3 & $65.67 \%$ \\
\hline $75-84$ & 366.2 & $87.18 \%$ \\
\hline $65-74$ & 143.2 & $95.59 \%$ \\
\hline $50-64$ & 50.6 & $98.56 \%$ \\
\hline $40-49$ & 15.7 & $99.48 \%$ \\
\hline $30-39$ & 6.3 & $99.85 \%$ \\
\hline $0-29$ & 2.5 & $100.00 \%$ \\
\hline
\end{tabular}

The corresponding Pareto Diagram of the data in Table 1 is shown in Figure 1.

Figure 1. Pareto Diagram of the covid-19 mortality rates in the US.

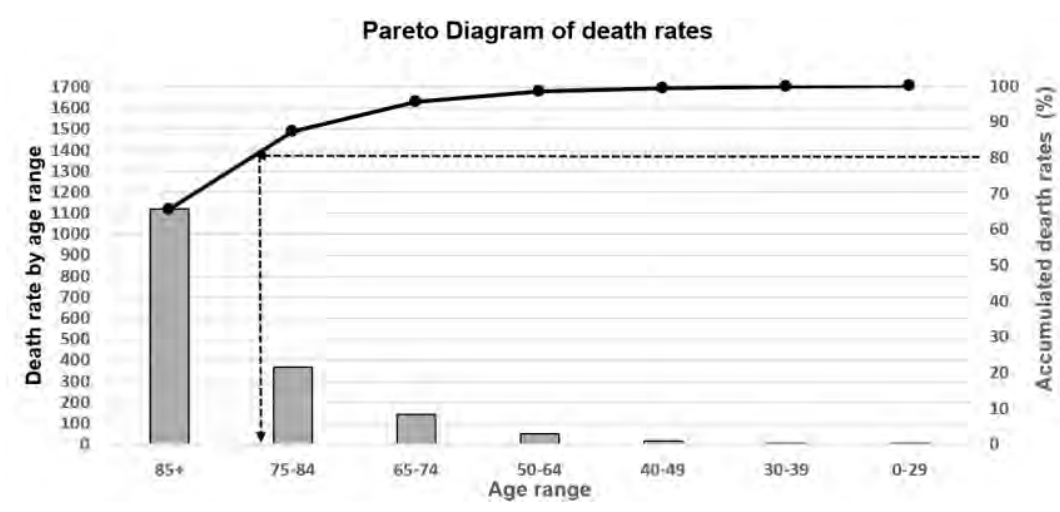

From Figure 1, it is noticeable that $65.67 \%$ of the deaths could be avoided if the population of 85 years old and older are vaccinated first. If the goal is to reduce $87.18 \%$ of the deaths, the adults 75 and older should be vaccinated. This is not so formidable because the people in the US having 75 years or more are only $6.8 \%$ of the whole population (De Wulf, 2019). In this way the hospitalizations would be greatly reduced leaving space for the less vulnerable population. The Pareto Diagram would change dramatically if life expectancy is considered in the United States. An argument could be made that older people would not live more than just a few more years while young people in the age range of 20-40 years old would still have more than twice their age to live (Schwab \& Malleret, 2020). If the "lost years" were taken into consideration, the column of the number of deaths could be multiplied by the potential lost years and the Pareto Diagram would look very different and therefore the prioritization for vaccination could change. Students learn that there are many aspects to be considered when analyzing problems, mainly during the covid-19 pandemic in which economics is weighted against the health of the population.

Once that a Pareto Diagram has been constructed the vital problems can be analyzed using other tools, or a Pareto Diagram could be elaborated for each of the most important problems. For example, Pareto Diagrams for the covid-19 mortality rates for the 85+ and the 75-84 age groups for states of the Union, comorbidities, races, socio-economical conditions, regional degree of urbanization, regional hospital infrastructure or medical resources or for other variables, could be elaborated. These Pareto Diagrams could be very useful because noticeable difference could be detected and if there is lack of resources an extra analysis could help to curb deaths more effectively. 


\section{Ishikawa diagram}

Sometimes, once that a Pareto analysis is carried out an Ishikawa Diagram is worked out for each of the vital problems. In an Ishikawa Diagram the problem is considered the effect and the causes are looked for, also for each cause there are sub causes which must also be found. Once that the Ishikawa Diagram has been constructed, another diagram can be easily drawn with the solutions to solve the problem. In the next example, an Ishikawa Diagram is used to analyze the problem of why distance learning has not been very successful in Mexico (Dominguez-Perez \& Dominguez-Vergara, 2020) (Dominguez-Vergara \& Dominguez-Perez, 2020). In this example the issues of courses which cannot be taught easily at distance, like laboratories, are not considered. Likewise, there are other problems which are not included, for example, power outages, because although important, they are considered sporadic.

Figure 2. Ishikawa Diagram for distance learning problems in Mexico.

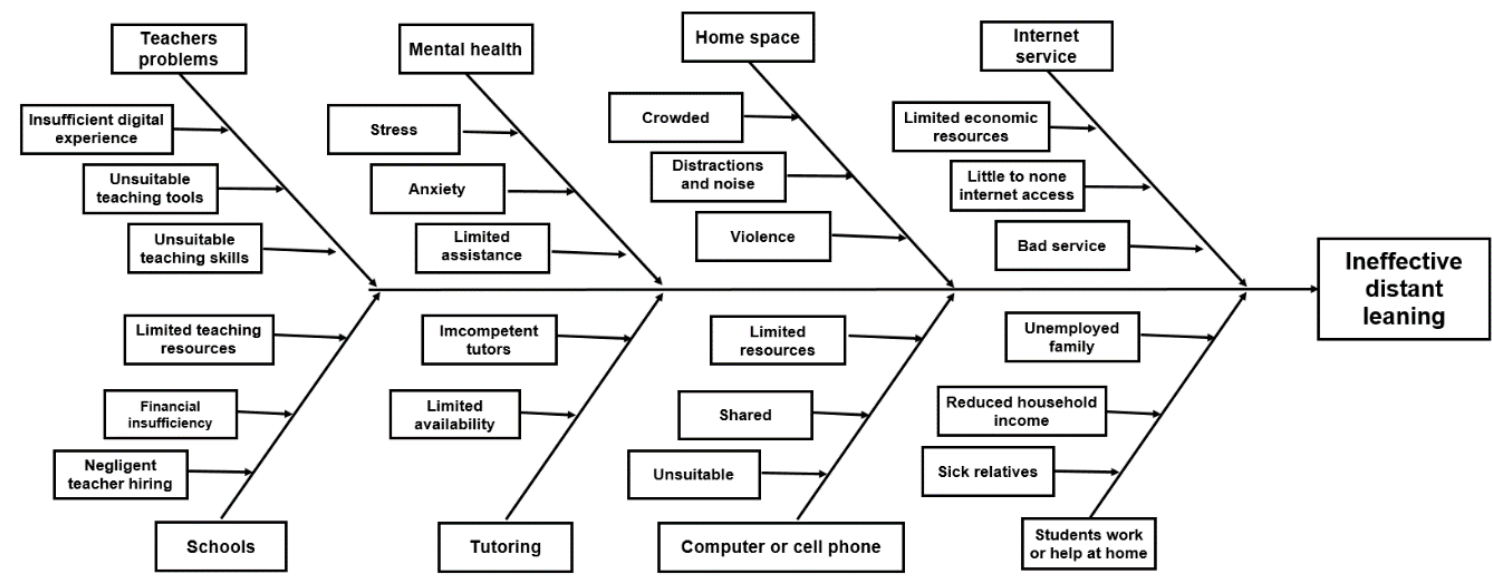

A very useful Ishikawa Diagram can be easily constructed if a very competent team acquainted with the problem participates. For example, in the US the vaccination priorities (effect) was reached after considering Science, Ethics and Implementation (causes) (US Center for Disease Control and Prevention, 2020 ) by a multidisciplinary group. Ishikawa diagrams have been explained in class by one of the coauthors of how to reduce contagion at home, and why in Mexico the number of deaths has been disproportionately high (because of lack of testing, confused government messages to the population and other causes.)

\section{Check list}

The Check List is a very useful tool which can prevent huge mistakes despite its simplicity. Students are given assignments to elaborate check lists to avoid contagion in shopping during the pandemic. The checks lists include precautions which must be taken leaving home, in the way to the supermarket, in the markets or supermarkets and in returning home, as it is explained in Table 2. A Check List Diagram can be very helpful instead of a simple list; however, sometimes just a list could be easier to review and handle. Although the Check List should be very detailed, in this example, a generic list was elaborated to stress the most important steps.

\section{Dispersion diagram}

Several examples of dispersion diagrams of two variables are explained to the students and homework is assigned in order that they practice their use. One of the variables could be an effect and the other the cause. Or both variables could be effects or causes which could be related. Also, the students must learn that sometimes it is necessary no to consider one of the variables or both of the variables directly but after being mathematical transformed. In the next example the relation between the number of contagious and the number of deaths for many countries is explored (Worldometer, 2021). The data corresponds to the 14 of February of 2021 and to the first 192 countries of the list in reference (Worldometer, 2021). Instead of using the variables directly the base 10 logarithms of the two variables are used. The results are shown in the Dispersion Diagram in Figure 3. 
Table 2. Check list of preparing, traveling to, visiting and returning from a supermarket.

\begin{tabular}{|c|c|c|}
\hline Activities & YES & NO \\
\hline \multicolumn{3}{|l|}{ 1. Before leaving home } \\
\hline Is your shopping list complete? & & \\
\hline Is the place and mode of transportation well defined? & & \\
\hline Will you pay with a debit or credit card? & & \\
\hline Are you already wearing a mask and carrying gel? & & \\
\hline If you are traveling by car, did you disinfect it? & & \\
\hline If you are traveling by public transport, do you have change? & & \\
\hline \multicolumn{3}{|l|}{ 2. During the journey } \\
\hline \multicolumn{3}{|l|}{$\begin{array}{l}\text { If you travel by public transport, do you follow the hygiene measures of that transport (face masks, } \\
\text { distance between passengers, open windows, etc.)? }\end{array}$} \\
\hline \multicolumn{3}{|l|}{$\begin{array}{l}\text { If you travel by public transport paying in cash, did you disinfect the change before and after } \\
\text { entering the vehicle? }\end{array}$} \\
\hline \multicolumn{3}{|l|}{ 3. At the supermarket } \\
\hline \multicolumn{3}{|l|}{$\begin{array}{l}\text { Did you follow the hygiene measures of the place when entering (cart handle cleaned with gel, } \\
\text { mask, distance from other visitors)? }\end{array}$} \\
\hline Did you follow the hygiene measures while inside the place (mask, distance from other visitors)? & & \\
\hline \multicolumn{3}{|l|}{ Did you check before paying that you carry all the products? } \\
\hline \multicolumn{3}{|l|}{ Did you follow the hygiene measures when paying (mask, safe distancing)? } \\
\hline \multicolumn{3}{|l|}{ Did you disinfect the change or your payment cards? } \\
\hline \multicolumn{3}{|l|}{ 4. On the way back } \\
\hline \multicolumn{3}{|l|}{$\begin{array}{l}\text { If you travel by public transport, do you follow the hygiene measures of that transport (face masks, } \\
\text { distance between passengers, open windows, etc.)? }\end{array}$} \\
\hline \multicolumn{3}{|l|}{$\begin{array}{l}\text { If you travel by public transport with cash payment, did you disinfect the change before and after } \\
\text { entering the vehicle? }\end{array}$} \\
\hline \multicolumn{3}{|l|}{ 5. At home } \\
\hline \multicolumn{3}{|l|}{ Did you disinfect the keys upon entering? } \\
\hline \multicolumn{3}{|l|}{ Did you disinfect or change your shoes when you entered? } \\
\hline Did you disinfect everything you brought (merchandise, clothing, shoes, etc.)? & & \\
\hline Did you bathe and change clothes? & & \\
\hline
\end{tabular}

The result in Figure 3 shows that there is a linear relation between the two variables considered. Students must learn to explore mathematical transformations of the variables and also to adequately treat the data. For example, in Mexico the authorities since April of 2020 declared based on insufficient information that the pandemic was under control and in August 2020 some extrapolation was made to establish that the pandemic was receding, when the worst weeks were coming in January 2021. Wrong conclusion was given because of insufficient data and insufficient analysis of the data.

\section{Stratification, histogram, decision tree, Shewhart charts and Poka Yoke}

There are many other tools learned and used by engineering students (Gutierrez \& de la Vara, 2013) which are not explained at length in this paper but only briefly in what follows. Students are recommended to use stratification of the data in studying many problems. For example, in studying deaths a stratification by sex is very important and it is easily seen that women die much less that men. For example by studying the population pyramids is found that in the US from the ages 0 to 39 years there are more men than women but after 55 there are more women than men (De Wulf, 2019). In Mexico there are more men than women in the ages 0 to 24 but in the ages 34 and more there are more women than men (De Wulf, 2019). Therefore, apparently women are more resilient than men in old ages and the coronavirus impact on deaths is not different because men are dying more that women. In the first example in this paper, a stratification by the age of the population was first carried out. There are many examples of stratifications carried out to explain that deaths by coronavirus have been disproportional in minorities in the US or to remark that minorities are being left behind in virtual education. Combination of Stratification and a Histogram should show that minorities working in essential activities have been more contagious by classifying the population by job activity, age range and race. A decision tree is very useful to analyze consequences of the federal authorities' decisions. For example, in Mexico flights from other countries were never prohibited, very few tests to detect coronavirus contagion have been carried out, also the use of masks was never enforced, even the Mexican President publicly refused to use them; the effect of this government's measures could be analyzed using a Decision Tree. Shewhart control charts (Gutierrez 
\& de la Vara, 2013) are also very useful to detect non-random events during the observations of variables in some periods of time (like the proportion of deaths in a country), examples using that tool will be reported elsewhere. Also, some Poka-Yoke tools (Gutierrez \& de la Vara, 2013) should be created to contain or avoid contagion, so far the best Poka-Yoke are social distancing, washing hands, use of masks and definitely the best and most important of them: the vaccine.

Figure 3. 10 base logarithms of the number of contagious people (horizontal axis) and the number of deaths due to covid-19 (vertical axis).

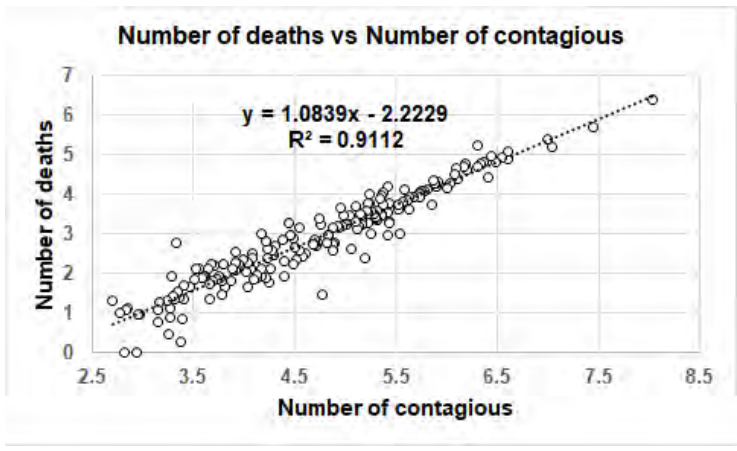

\section{Conclusion}

Quality control tools are very useful to analyze many formidable problems and make useful recommendations beyond engineering.

\section{References}

De Wulf, M., (December 2019). Pirámides de población del mundo desde 1950 hasta 2100, Estados Unidos. Retrieved 14 February, 2021, from: https:/www.populationpyramid.net/es/estados-unidos/2020/

De Wulf, M., (December 2019). Pirámides de población del mundo desde 1950 hasta 2100, Mexico. (December 2019). Retrieved February 14, 2021, from: https://www.populationpyramid.net/es/m\%C3\%A9xico/2020/

Dominguez-Perez, D.N., \& Dominguez-Vergara, N. (2020). From the lessons of coronavirus, a whole new world in education? EDULEARN 2020 Proceedings. pp. 6412-6421.

Dominguez-Vergara, N., \& Dominguez-Perez, D.N. (2020). Some impacts of covid-19 to higher education in Mexico. ICERI 2020 Proceedings. pp. 3691-3700.

Gutierrez, R., \& de la Vara, R. (2013). Control estadistico de la calidad y seis sigma. Cd. de Mexico/Mexico: McGraw-Hill/Interamericana.

Schwab, K., \& Malleret, T. (2020). Covid-19: el gran reinicio. Coppell, TX/USA: Forum Publishing.

US Center for Disease Control and Prevention. (December 2020). Phased allocation of covid-19 vaccines. Retrieved February 14, 2021, from: https://www.cdc.gov/vaccines/acip/meetings/downloads/slides2020-12/slides-12-20/02-COVID-Dooling.pdf

Worldometer. (2021). Covid-19 coronavirus pandemic. Retrieved February 14, 2021, from:https://www.worldometers.info/coronavirus/ 